\section{A OCliniral aperture}

ON

\section{THE SURGICAL ASPECTS OF SPINAL IUUMOURS.}

Delivered at the National Hospital, Queen Square. $\mathrm{BY}$

PERCY SARGENT, C.M.G., D.S.O., F.R.C.S., SURGEON TO ST. THOMAS'S HOSPITAL AND TO THE NATIONAL
HOSPITAL, QUEEN SQUARE.

IN 1881 the late Mr. Frederick Page of Newcastle wrote as follows: "The operation of trephining the spine, proposed many years ago and adopted several times, has made no progress in surgery; nor is it likely to do so. It is an operation not within the range of practical surgery."1 It was only a few years later that Sir Victor Horsley, in 1887, deliberately opened the spinal canal and removed a tumour from between the membranes and the cord. 'This operation gave the first effective impetus to the development of spina surgery, and there is no single landmark in surgical history which stands ont with greater distinctness.

This classicai case, which marks the real beginning of the operative surgery of the spiual cord, may be briefly recalled. The patient was a man, uncler the care of Sir William Gowers, 42 years of age, who had suffered for three year's from a peculiar pain localized to a spot beneath the lower part of the left scapula, increased by exertion and varying in severity from time to time, with intervals of freedom. Four months before the operation the left leg became weak, and a few weelis later the right leg became similarly affected. During the next two months sensation became impaired and urinary retention appeared. The condition was regarded by various physicians as aneurysm, intercostal neuralgia, or hysteria. At the time of the operation there was complete paraplegia, with loss of all forms of sensibility up to the level of the ensiform cartilage. Just above this level there was severe girdle pain, worse on the left side than on the right, and increased to agony on any movement. There was some diminution of tactile sensibility up to the fourth intercostal space. A diagnosis of tumour pressing upon the cord was made by Gowers, and in June, 1887, Horsley removed tho arches of the first six thoracic vertebrae and exposed an almond-shaped tumour, of a darls bluish-red colour, resting upon and attached to the left fourth thoracic nerve jammed between the dura mater and the spinal cord. The growth proved to be a fibromyxoma. A year later tho patient was doing his full day's work, which necessitated much walking and standing about. ${ }^{2}$

Since that date not only have large numbers of similar tumour's been successfully removed, but also intramedullary tumours have been enucleated, intramedullary cysts and the cavities of syringomyelia have been incised, and many other pathological conditions causing symptoms of compression of the spinal cord have been successfully dealt with through the opening afforded by the operation of laminectomy.

The following remarks are based upon a series of 27 cases which I have operated upon cluring the past ten years. These are all cases of true neoplasm of one sort or another associated with cord symptoms; all cases of syphilis, tuberculous disease, and cyst are excludel.

Of the various ways in which these tumours may be grouped I prefer to take the regional rather than the listological. On this basis they fall into three groups, according to whether they are (1) intrathecal but extramedullary, (2) intramedullary, and (3) extratliecal.

Intrathecal extramedullary tumours present themselves either as definitely encapsuled masses, which are almost invariably of a benign nature, or as diffuse masses of growth extending over a somewhat large area, whether of the cord itself or of the cauda equina, and histologically of a malignant character.

\section{ENCAPSULED INTRATHECAL EXTRAMEDULLARY TUMOURS}

Fifteen of the twenty-seven cases belong to this class. They possess a cortain similarity in size, appearance, cncapsulation, and relationship to the cord. With a single exception ("fibrosarcoma") the histological characteristics* of this class are those of benign tumours, namely:

$\begin{array}{llllll}\text { Neurofibroma } & \ldots & \ldots & \ldots & \ldots & 4 \\ \text { Endothelioma } & \ldots & \ldots & \ldots & \ldots & 3 \\ \text { Psammoma... } & \ldots & \ldots & \ldots & \ldots & 3 \\ \text { Fibroma } \ldots & \ldots & \ldots & \ldots & \ldots & 2 \\ \text { Fibromyxoma } & \ldots & \ldots & \ldots & \ldots & 2\end{array}$

Such tumours may be firmly attached to the iuner aspect of the dura mater or to a nerve root. On the other haud, their connexions are sometimes so flimsy that they appear to lie almost free in the arachnoid, and they cau be picked ont without causing any haemorrhage, and without it being possible to determine their actual point of origin. At the level of the tumour the whole thecal lumen may be so filled up that the cerebro-spinal fluid above has little or no communication with that below. Hence pulsation is only to be seen above the tumour, and this may be a valuable topographical indication during au exploratory operation. When such a tumour has been removed, thcre remains a scaphoid depression in the cord which does not appreciably alter either in size or in depth during the time that the cord is exposed, despite the fact that the displaced cord usually moves so as to occupy more nearly its natural position. In some very long standing cases the cord appears to be flattened to a ribbon, so that one wonders how any impulses at all can be conducted through it.

The situation of these tumours in relation to the cord is most commonly postero-lateral-that is, the cord is displaced forwards and towards the opposite side (7 cases); it may be in tho middle line posterior to the cord (2 cases); antero-laterally situated so as to push the cord backivards and towards the opposite side (4 cases); or anterior to the cord so as to be invisible until the cord is drawn aside ( 2 cases).

Segmental Level.

In neither of the fifteen cases under review was the tumour situated above the fifth cervical or below the eleventh thoracic segment. The actual situations were C.5, C.7, D.1, D.2 (3 cases), D.3, D.4, D.5 (2 cases), D.7 (2 cases), D.8, D.10, and D.11. In each case the segment quoted is the uppermost reached by the tumour.

\section{Symptomatology.}

There does not appear to bo any constant relationship between the position of the tumour, as regards the cord, and the incidence of the symptoms. The order in which these make their appearance is very variable.

\section{Pain.}

The most usual initial symptom is pain, referred to the area of distribution of one or more of the spinal nerve roots. This was the first symptom in eight of the fiftecn cases. It may be very severe and persistent, or it may amount to nothing more than an unpleasant sense of constriction, and it may for many months or eren years be the only cause of complaint.

This circumstance is sufficiently striking to suggest that in any case where severe and persisteut pain, localized to the distribution of one or more nerve roots, cannot be satisfactorily accounted for, the possibility of a spinal tumour being present should be seriously considered.

Pain in the back is not a common occurrence in cases of spinal tumour of this class. When it has been present in three of these fifteen cases) it has been the first symptom of which the patient has complained, has been unaccompanied at any time by root pain or girdle sensation, and has preceded the other symptoms by some months. In no case has any tenderness, rigidity, deformity, or abnormal radiographic appearance been noted.

$\Lambda$ third type of pain of which these patients may com. plain is "pain in the legs." With tumours involving the cauda equina, such pains are naturally of the same character and causation as root pains elsewhere. Isut patients with tumours at a higher level sometimes com. plain of pain in the legs. Usually, on close questioning, it is obrious that these pains are associated with spastic involuntary contractions of the muscles, but in other instances this does not appear to be the explanation. It is possible that in some cases at least the pain is

* I am indebted to Dr. J. G. Greenficid for a recent re-examination of all theze tumours. 
dependent upon variations of pressure in the cerebrospinal fluid. 'The thecal canal may be so fully occupied at the level of the tumour that the fluid pressures above and below may be different, and it is possible that in such circumstances a sudden exertion on the part of the patient may drive down a smalbquantity of fluid past the block so as suddenly to increase its tension to a point at which pain is produced. This seemed to be the explanation of the "sharp shooting pains down both lips and thighs" in one case, where the tumour was found to block the thecal caual at the level of the eighth thoracic segment.

In a recent case, not included in this series, pain in the left thigh and leg, of "sciatica" type, was for a long while the most prominent symptom, the tumour being a small hard encapsuled "psammoma" cupping the lateral aspect of the cord at the level of the eighth thoracic segment on the right side. This suggests direct pressure by the tumour upon the pain fibres in the antero-lateral column.

In a series of 33 cases of intramedullary tumour recorded by Horsley pain was the first symptom complained of in 21 .

\section{Paracsthesia.}

"Numbness" in the legs is often complained of (9 cases), but always in association with weakness. Impairment of sensibility of a more definite character is sometimes noticed by the patient. Thus, one patient found that one leg was less sensitive to pain than the other; another that one leg always felt cold; another that "she could not feel the water on her legs in the bath."

\section{Motor Symptoms.}

Weakness of the logs had been present before operation in all the cases, and varied from slight impairment to complete loss of all voluntary movements. In ihreo instances "stiffness," "jerking," or weakness was the first symptom noticed by the patient. In one of these cases the wealrness preceded the onset. of root pain by twelve months, and in the other two no root pain at all was complained of.

With a single exception the woak or paralysed legs were spastic, though never to an extreme degree. It is instructive to note that the one patient whose paralysed legs were stated to be "somewhat flaccid," had been unable to walk for seven year's, and that no motor improvement had occurred inore than five years after removal of the tumour.

Impairment of Sphincter Control.

It is a very striking fact that in eight of the fifteen cases there was no impairment of vesical function at any time, even though other symptoms had been present for periods varying from one to three years. In most of the other cases the impairment of function amounted to littlo more than precipitancy or hesitancy of micturition, usually the former. Very rarely is a catheter required. As would be expected, therefore, cystitis is an uncommon complication, and one that is comparatirely easily dealt with if it does occur. This contrasts strongly with the gross impairment of function and the fulminating cystitis so common in cases of paraplegia of more rapid onset.

\section{Nedrological Examination.}

The date at which sensibility first becomes affected cannot be ascertained, as the patients are often unaware of any impairment, unless it is of a particularly gross character. The greatest diversity of symptoms exists in this respect, as would naturally be expected from the variations in position of the tumours, the different degrees of pressure exerted by them, and the extreme slowness with which the compression advances. Frequently the upper limit of the sensory change is not abrupt, as it is in the case of a more sudden and severe lesion; and as in a certain proportion of cases (five out of fifteen) there are no root symptoms to afford a guide, it becomes a matter of the utmost importance, for localization, to examine carefully for the uppermost limit of even the slightest dif. ferences in appreciation of the various sensory stimuli. In this respect repeated examinations are necessary, as varia. tions in the upper level of slight changes are met with from time to time.

The Brown-Séquard syndrome is frequently met with. In several of the cases it was well marlzed when the patients first came under observation. In the majority a definite history was obtained of one leg becoming affected before the other.

When the tumour is related to one of the lower thoracic segments the abdominal reflexes may afford a more valuable localizing sign than the level of sensory change.

\section{Clinical Course and Prognosis.}

The course pursued by a case of spinal tumour is characteristic. It is slow, but remorseless. There is rarely any appreciable halting, more rarely still any temporary amelioration, and gradually the symptoms progress to the inevitably fatal termination unless relief is afforded by operation. It is in this field that the science of neurology and the art of surgery combine to achieve one of their greatest triumphs.

Horsley stated the average total duration of the symptoms in these cases of simple tumour to be three and two-thirds years. In the present series of fifteen cases it was two years, despite the fact that one patient had had symptoms for no less then nine years. It is to be hoped that the future will show a still greater improvement in this respect, as the condition becomes recognized at an earlier date.

It would be expected that the rapidity and completeness of recovery after operation would be materially affected by the length of time during which the cord had been subjected to pressure. Whilst this cannot be denied, it is true only within wide limits. Whereas in the majority of cases in which a complete or practically complete recovery occurred weakness had been present for less than twelve months, yet in one instance the legs had been weak for nearly three years. On the other hand, one patient who had been virtually paralysed for eight years showed no sign of motor recovery five and a half years after removal of the tumour. The most striking immediate result of operation is the relief of pain. This may be con. fidently predicted whatever may have been its previous duration, and whether or not nerve roots are divided when the tumour is removed.

Power, as a rule, begins to return before sensation. In a favourable case a definite improvement in voluntary power may be observed to take place within a week of the operation. In one patient the weakness had been coming on gradually for nine months, and at the time of the operation the legs were spastic and no voluntary move. ments were possible; the sensory loss was complete. In ten days power began to return and in eight weeks he was beginning to wall, but no return of sensibility to pin-prick or to cotton-wool was detected for nine weeks. In another patient with nine months' history, where spastic wealrness and partial loss to all forms of sensibility were present at the time of the operation, power was rapidly returning in three weeks, but sensation was unaltered. The sensory return takes place uniformly over the affected area, the original level remaining distinguishable throughout. In two cases, examined respectively five and six years after operation, although recovery was in all respects practically perfect, the old level could still be definitely ascertained by a distinct difference to pin-prick above and below.

Four cases operated upon between five and six years ago have recently been examined with a view to ascertaining the degree of the completeness of the recovery. The chief points may be very briefly summarized as follows:

Endothelioma at Level of Fourth Thoracic Segment.

Female, aged 71 (under the care of Dr. James Collier). Fifteen months' history. Extreme spasticity; slight voluntary movements in right lower limb, none in left; profound loss to all forms of sensation; no sphincter trouble; bedsores. Tumour completely removed.

Six years after operation, in perfect health. No ascertainable weakness of legs; deep reflexes normal; plantars flexor; position sense and localization perfect; no loss to cotton-wool pin-prick well appreciated everywhere, but it "gets sharper" when old level is reached.

Neurofibroma at Level of Tenth Thoracic Segment.

Male, aged 35 (under the care of Dr. Tooth). Twelve months' history. Severe root pain; lower limbs extremely spastic; no history. Severe root pain; lower limbs extremely spastic; no voluntary movements ; complete loss to all
below level. Tumour completely removed.

Five and a half years after operation was doing full work as Five and a half years after operation was doing full work as
an agricultural labourer. Says left leg feels weaker than right. an agricultural labourer. Says left leg feels weaker than right. No difference in power detected; powerful muscular limbs; deep reflexes normal ; abdominals absent ; plantars extensor;
no losz detected to touch, pin-prick, or localization; position sense in left foot very defective. 
Fibromyroma at Level of Seventh Cervical Seqment.

Male, aged 32 (under the care of Di. James Collier). Nine months' history. Pefore operation upper limbs weak and flaccid; intrinsic muscles of hands wasted; neuralgic pains in uhar fingers; muscles of trunk and lover limbs very spastic no voluntary movements in right lower limb; feeble in left; profound loss to all forms of sensation to level of C.7; dysuria. i'umour completely removed.

Five yeass alter operation was doing full work as a letter sopter. No clumsiness or weakness in hands; no wasting; no pain; no sphincter trouble; deep reflexes somewhat brisk; abdominals present and plantar; flexor; no sensory loss detected, but ola level can still be mapped out by a slight dulling to piu-prick below.

In coutrast to the foregoing the following may be re?atcd:

Psammoma at Level of Secinth Thoracic Sedment.

Female, aged 32 (under the care of Dr. 'Tooth). Pain in back nine years and weakness of less eight years before operation. On examination, complete loss to all forms of sensation; complete motor pa!sy with ankle clonus; plantars extensor; precipitancy of micturition.

five and a half years after operation, no recovery of powe whatever. Sphincter control normal; appreciates cotton-wo vhatever. Sphincter control normal; appreciates cotton-wo cold tubes merely as unlocalizable touch.

\section{Operative Tiechivioue.}

The proceduro adopted in all cases is practically tho same as that cinployed by Horsley, except for the method of anaesthesia. Chloroform and intravenous hedonal, which Dr. Mennell administered for me in a few cases, luave been discarded in favour of ether given by the intri trachea! method. I do not believe that, provided cyanosis is avoided, the haemorrhage is any greater wi. ether than with chloroform; whilst the abolition of the respiratory movements, and in cervical cases the being able to have the neck flexed as acutely as may be desired, is of great assistance. 'The amount of blood lost depends more on the surgeon's technique and resource than upon tho auasthetist.

If the fir'st stages of the operation are conducted rapidly under a stream of normal saline solution at $118^{\circ} \mathrm{F}$. and time is not wasted in cndeavouring to scize individual bleeding points with forceps, tho amount of blood lost need not be great. 'The spinous process corresponding to the position of the tumour is first marked by a transperse scratch on the sliu, and then a median vertical incision is made with this mark as its centre. The muscles aro rapidly stripped from the bones, and then at least five spinous processes are cut away at their bases with strong forceps. If now the largo wound is packed tightly for a fow minutes with gauze, it can be renclered remarkably dry, and the rest of the opsration should by almos' bloodless.

'The laminal arches are next removed with Horsley's laminectomy forceps, cxposing the layer of fat suriounding the thec.l. This has to be stripped off, and the theca cain then be examined. Sometimes the tumour can be easily felt at this stage, or a difference of thecal pulsation above and below may indicate its position. I always endeavou to open the dura, by a median vertical incision, without wounding the arachnoid. In this manner a beautiful view of the tumour is obtained, seen through the transparent arachnoid, and its relations to the cord and nerve roots accurately ascertained. If the cerebro-spinal fluid is allowed to escape the posterior nerve roots, which normally float free, fall against the cord, so that their real relationship to it and to the tumour cannot be determined. I have several times seen the tumour, through the unopened arachnoid, moving up and down for a short distance like a shuttle, with the pulsations of the cerebro-spinal fluid.

'The araclinoid is next torn through and the tumour can then be gently lifted out of its bed with some small blunt instrument. If necessary a nerve root or a tooth of the ligamentum denticulatum must b3 clivicled. It should hardly be necessary to state that this part of the operation must be conducted slowly and with the utmost gentleness.

The theca should be sutured and the muscles brought accurately together, preferably in two separate layers, in order to avoid any chance of lcakage.

\section{Post-operatrve Dangers.}

Leakage of cerebro-spinal fluid is a dangerous complication. It introduces the possibility of meningitis, and, apart from that, the patients usually suffer a good deal in general health, for the total amount of fluid lost may be enormous.
Two of my patients have died suddenly within forty-eight hours of the operation, the tumours having been removed from alongside the upper thoracic part of the cord.

Other occasional causes of serious symptoms, which may terminate fatally, are acute dilatation of the stomach, and paralytic ileus.

\section{Results.}

Of the 15 cases in this series, 11 may be described as in all respects satisiactory. Of these patients 6 are (or when last heard of were) doing their full ordinary work; another, 77 years of age, is in perfect health and vigour, and the other 4 are so far recovered that they may reasonably be regarded'as successful cases. Of the 4 unsuccessful results 1 (whose paralysis had existed for nine year's before operation) remains virtually in statu quo five and a half years afte: removal of the tumour. 'I'se remaining 3 patients died. They arc instructive cases, and may be very briefly quoted:

CASE I.

W. L., male, aged 47. After having suffered pain in the back for fifteen montis, and increasing weakness in the legs for ten months, was admitted to the National Hospital under Dr. James Taylor. On admission he had spastic paraplegia, almost complete, with impairment of sphincter control, and almost total plete, with impairment of sphincter control, and almost total thoracic segment.

A laminectomy was performed, and the cord exposed from the sixth thoracic to the first lumbar segments. No sign whatever of a tumour could be found. Seven weeks after this unsuccessfui exploration he had voluntary movements at all joints of the lower limbs, less involuntary spasm, and much less complete sensory loss, together with considerable improvement in sphincter control. He left hospital much improved, but was readmitted two years later in practically the same condition as he had been prior to the first operation. It was de. cided to attempt. to relieve the distressing muscular spasms, and accordingly another laminectomy was performed, and the pos. terior recond, third, and fifth lumbar and the ter divided on both sides. Five days second sacral nerves were divided on the bides.

ater he died from paralytic distension of the bowel. Post mortem an endothelioma 23 by $1 \frac{3}{4} \mathrm{~cm}$. Was found, attached firmly to the dura, lying wholly in front of the eleventh thoracic segment, which was flattened to a ribbon over it. The par-
ticularly interesting points in the case are (1) that the tumour ticularly interesting points in the case are (1) that the tumour
was in an unusua! position and completely out of sight, (2) that was in an unusual position and completely out of sight, (2) that at no time were any root pains experienced, (3) that pain in the back had existed for six months before the onset of any other symptoms, (4) that death after the second operation was due to paralytic ileus, and (5) that the mere relief of pressure afforded
by the first operiation was followed by a considerable degree of temporary improvement.

Case II.

Male, aged 59 (under the care of Dr. Risien Russell). When first admitted to the National Hospital he had suffered from girdle pain at the twelfth thoracic level for five months, and dragsing first of one leg and then of the other for four months. He had no sphincter trouble; both legs were weak and spastic, He had no sphincter trouble; both legs were weak and spastic,
the right more so than the left. The sensory loss was almost the right more so than the left. The sensory loss was almost complete to all forms, up to the twelfth thoracic level on the
left side. Three weeks later, whilst the girdle sensation perleft side. Three weeks later, whilst the girdle sënsation persisted at the same level, the level of sensory loss had moved upwards and spread to the opposite limb. Three months later there was sensory loss up to a definite level-that of the third
thoracic segment. The legs were much worse and very spastic; thoracic segment. The legs were much worse

slight hesitancy of micturition had appeared. A fir of a small marble, was removed from in The operation was easy and without untoward incident, and all went well until thirty hours later, when he died quite suddenly and without varning

Post mortem nothing was found to account for his death.

\section{CASE III.}

Female, ager 34 (under the care of Dr. James Taylor). Two years' history of stiffness and weakness in the legs, abdominal girdle pains, and loss of feeling in the legs. No sphincter trouble.

A firm tumour, attached to the right eighth cervical posterior root, was easily removed. It was pronounced microscopically to be a fibrosarcoma. All went well for nine clays, when removal of the stitches was followed by leakase of cerebro-spinal fluid. This continued, and a month after the first operation the muscles were re-sutured. Meanwhile a considerable degree of improvement had occurred both as regards power and sensation, and the general condition had remained excellent. Some thirty hours after the closure of the wound she died quite suddenly.

Pust mortem nothing was discovered to account for the death.

\section{OTHER FORMS OF SPINAL TUMOUR.}

Twelve cases of tumour causing cord symptoms, other than the encapsuled intrathecil extramedullary type, were encountered during the same period. They contras strongly in many ways with the others. In the first place the tumours were, without exception, of a malignant 
character, though their degrec of maliganncy, judged clinically, was extremely variable.

I classify these tumours, according to their probable point of origin with relation to the cord, into three groups: (1) Intrathecal extramedullary, (2) intramedullary, (3) extrathecal.

The membranes constitute an almost if not absolutely impermeable barrier to the spread of these gruwths, so that we rarely find any overlapping between these three groups. All tend to spread upwardis or downwards in a direction parallel with the cord, confined within the limits of the pia or dura as the case may be. In only one casc did an intradural tumour gain the exterior of the theca, and that was through the operative incision.

With the upward spread of the tumour mass there develops a gradual compression of the cord, which progressively reaches a higher level. Hence we find that with malignant tumours there is often a varying upper. limit of sensory change, together with root pains spread over many segmental areas. 'These are important points in the diagnosis between diffuse malignant tumours on the onc hand and the more definitely localized encapsulated tumours on the other.

\section{Lavel and Symptoms.}

In the three cases of non-encapsuled extramedullary intrathecal tumours, all sarcomatous, the tumour involved the cauda equina, and the nerve roots were surrounded by growth. Nevertheless, radiating pain was absent in two of them; in these two pain in the back was noticed early. Loss of sphincter control was an early and prominent symptom in two instances; is both of these the growth surrounded the conus medullaris.

The cases of intramedullary tumour contrast strongly with these extramedullary malignant ones, for in the former weakness and numbness in the limbs is the earliest symptom, though in one of the four radiating pains had occurred before any other symptom. Again, sphincter disturbance is slight or absent as a rule in the intramedullary cases.

If we compare the incidence of the symptoms in cases of extrathecal tumour due to malignant disease of the bones, whether primary or secondary, we find pain, either local or radiating, to be the first symptom, and usually it is of an extremely severe character and is increased on move. ment. Sphincter disturbances are not much in evidence in these cases.

Whilst $x$-ray examination has so far been uniformly negative in other forms of tumour, it usually gives valuable help in the cases of tumour arising in the bones. We cannot, however, in this manner distinguish between malignant disease and tuberculous caries; and even when exposed by operation the granulation mass, in some cases of tuberculosis, has so closely resembled tumour that only by microscopical examination has the true nature of the case been ascertained.

In none of the 12 cases of malignant growth in this series was the exact nature of the case diagnosed before operation. The fact that the cord was being subjected to an increasing degree of compression led in each instance to the performance of an exploratory laminectomy, and in all but one the diagnosis of "tumour" was made before operation (one was thought to be tuberculous caries); in all, too, the segmental level of the compression was correctly ascertained before operation. But in no instance could the exact position with relation to the cord and membranes, or the nature of the tumour be foretold. The operations were therefore primarily of an exploratory character.

\section{Results.}

Two patients-one with a high cervical intramedullary tumour, and the other with a sarcoma of bone in the upper dorsal region-died within a few hours of the operation. The rest may be briefly set out as follows:

A. Diffuse Intrathecal Extramedullary Growths. Male, aged 49. Died, unimproved, ten months after exploratory laminectomy.

Female, aged 22. Left hospital, unimproved, two months after removal of tumour, and was lost sight of

Male, aged 64. Improved so much after partial removal as to be able to return to business, but after six months relapsed, and died ten months after the operation.
13. Intramedullary 'Tumours.

Nale, age 33. Incision of coril over tumour. Improvel considerably and lived six and a half years.

Male, ared 59. Enucleation of tumour. Improved greatiy, hen relapsed and died two years and two months later.

Female, aged 45 . Incision of cord over tumour. Soma improvement at the end of three months.

\section{Firtrathecai Tumours.}

Male, age 33 . Decompression of theca aud corl. Improved very greatly and lived seven years.

Female, aged 55. Decompression. No improvement after two months; lost sight of

Female, aged 60. Decompression. Greatly improved at the Female, aged 60. Decompression. Greatly
end of ten months; lost sislit of afterwards.

Male, aged 41 . Decompression. Slight improvement after Male, aged
four months.

It might seem from a cursory glance at these facts that surgery has little to offer in such cases. It is not easy to put into words, still less into tabular form, what theso patients do gain by surgical intervention,. The most striking benefit is the relief of pain, a benefit which in most cases is in itself sufficiently great to justify the operation. This is a palliative measure of the first im portance. In some cases sphincter control has been im. proved, but I would not lay much stress upon this point seeing that in general the cases which have dono best have been those in which there was little or no disturbance of sphincter function before the operation.

In several cases power and sensation have so far been restored as to enable a bedridden patient to get about and even for a few months to attend to his business. But in estimating the valve of operative treatment, the subject of compression paraplegia must be considered as a whole. The causes, other than tumour, are many, and the differentiai diagnosis is difficult. Loculated collections of fluid (the "moningitis circumscripta serosa" of Horsley) post-gummatoús stricture, simple encapsuled tumours, and cold abscess, are conditions which can often be diagnosed with certainty by operation alone, and all these are lesions after removal of which, if the cord has not been too long subjected to pressure, recovery is to bs expected.

\section{CONCLUSION.}

The chief lesson to be learnt from the study of a series of cases of compression of the cord is that early exploratory operation should be more frequently undertaken. Neithe should a clear history of syphilis nor the existence of a positive Wassermann reaction be considered as a contraindication for operation should improvement not rapidly follow the administration of antisyphilitic remedies. For persons with active syphilis may suffer from spinal neo plasms (three out of tifteen of my cases of simple extra medullary tumour), whilst a constriction of the cord by fibrosis following gummatous meningitis, incapable of being influenced by drugs, may be successfully dealt witl by operation.

${ }^{1}$ Quoted by Horsley, MEed. Chir. Trans., 1xxi. ${ }^{2}$ Ibid.

\section{PUBLIC HEALTH VERSUS THE STATE.:} BY

BERTRAM G. M. BASKETT, M.B., B.CH.Oxon., RAYLEIGH.

Nearly seven years ago I spolse at a meeting of this Division and prophesied that the sequel of the Insurance Act would inevitably be an increase in deaths from tubercle. I was called to order; it was ruled that any other aspect was irrelevant than that which had rofer ence solely to the interests of medical men. I am here to-day not to say that my prophecy was true, for you all know that as well as I, but first to show the grounds on which my prophecy was founded, and secondly, to ask you to say that the ruling that such a topic was irrelevant was wrong, inasmuch as to have insisted from the first that the Act could not be in the interests of the public health would have averted the confusion of to-day, and completely frustrated the menace which now confronts the profession.

I may take it for granted that everyone will agree that it is a reproach to a civilized community that a preventable

* An address delivered before the South Essex Division, Britisl Medical Association, October. 1919. 